\title{
PODER CORPORATIVO E AÇÃO ECONÔMICA: reflexões a partir da mineração de ferro ${ }^{1}$
}

\section{CORPORATE POWER AND ECONOMIC ACTION: considerations on iron ore mining}

\author{
Rodrigo Salles Pereira dos Santos* \\ Bruno Milanez ${ }^{*}$
}

\begin{abstract}
Resumo
O trabalho discute a noção de poder corporativo a partir da comparação de três contextos mineradores em Minas Gerais, entre 2010 e 2015. A discussão teórica mobiliza criticamente os usos da categoria na geografia econômica (centrada no modelo de Redes Globais de Produção) e na sociologia econômica, destacando problemas teóricos e analíticos. Assim, defende uma perspectiva tridimensional (Lukes, 2005), capaz de integrar as formas externa (aberta e fechada) e interna de seu exercício; e um enquadramento relacional e positivo do poder, do qual emergem efeitos restritivos e extensivos em situações de interação entre agentes econômicos e não econômicos. A comparação dos casos da Anglo American/ Conceição do Mato Dentro (CMD), Companhia Siderúrgica Nacional (CSN)/ Congonhas e Vale/ Itabira utilizou predominantemente a observação direta e entrevistas semiestruturadas, permitindo verificar que: i. em Congonhas, a expansão em um contexto brownfield impulsionou formas de contestação que desafiaram institucionalmente ( $1^{\mathrm{a}}$ dimensão) a CSN; ii. o impedimento à ascensão como questão pública ( $2^{\mathrm{a}}$ dimensão) dos conflitos configurou a ação econômica nas condições greenfield de CMD, restringindo o exercício das formas institucional e coletiva de poder; e iii. o fim de ciclo mineral em Itabira permitiu a extensão do poder corporativo a uma dimensão interna, mobilizando subjetivamente ( $3^{\text {a }}$ dimensão) a adesão individual e coletiva e produzindo um regime de consenso desfavorável à contestação.
\end{abstract}

Palavras-chave: Ação econômica. Poder corporativo. Corporação transnacional (CTN). Mineração de ferro.

\begin{abstract}
In this paper, we discuss the concept of corporate power, drawing on the comparison of three mining sites in Minas Gerais (Brazil), between 2010 and 2015. The theoretical discussion scrutinizes the way the notion has been used in economic geography, namely by the proponents of the Global Production Networks (GPN) framework, and in sociology, highlighting theoretical and analytical issues. We argue for a three-dimensional perspective (Lukes, 2005), in order to integrate both the external (open and closed) and the internal modes of exercising power. In parallel, we stand for a relational and positive framework of power, from which both restrictive and extensive effects arise in interactions between economic and non-economic actors. Comparison of the (1) Anglo American / Conceição do Mato Dentro (CMD), (2) Companhia Siderúrgica Nacional (CSN) / Congonhas, and (3) Vale / Itabira cases predominantly has relied on direct observation and semi-structured interviews. The results
\end{abstract}

1 Os autores agradecem à Fundação de Amparo à Pesquisa do Estado do Rio de Janeiro (FAPERJ), à Fundação de Amparo à Pesquisa do Estado de Minas Gerais (FAPEMIG) e ao Conselho Nacional de Desenvolvimento Científico e Tecnológico $(\mathrm{CNPq})$ pelo apoio à pesquisa que deu origem ao trabalho; e aos comentários e sugestões dos pareceristas anônimos.

* Professor do Departamento de Sociologia e do Programa de Pós-Graduação em Sociologia \& Antropologia (PPGSA), Universidade Federal do Rio de Janeiro/Brasil. Doutor em Ciências Humanas pela UFRJ/Brasil. E-mail: santosrodrigosp@gmail.com

${ }^{* *}$ Professor do Departamento de Engenharia de Produção e Mecânica e do Programa de Pós-graduação em Geografia (PPGEO), Universidade Federal de Juiz de Fora/Brasil. Doutor em Política Ambiental pela Lincoln University/ Nova Zelândia. E-mail: bruno.milanez@uff.edu.br 
have shown that: (1) in Congonhas, growth of extraction in a brownfield site boosted social contestation modes that have challenged CSN on an institutional level ( $1^{\text {st }}$ dimension); (2) economic action in a greenfield setting (CMD) has prevented the conflicts to ascend as a public issue ( $2^{\text {nd }}$ dimension), and restricted the exercise of institutional and collective forms of power; and (3) the end of the mining cycle in Itabira has allowed the internalization of corporate power, by mobilizing ( $3^{\text {rd }}$ dimension) individual and collective acceptance, and has produced a consensus regime to the detriment of contestation.

Keywords: Economic action. Corporate power. Transnational corporation (TNC). Iron ore mining.

\section{Introdução}

Este artigo pretende realizar uma contribuição pontual ao debate sobre ação econômica e sua construção social, enquadrando-a em contextos multiagente. Essa contribuição diz respeito às condições de efetivação de decisões empresariais e aos recursos e formas específicas de influência mobilizados predominantemente por agentes econômicos, em contextos de interação com agentes políticos e sociais.

O trabalho propõe uma discussão teórica acerca dos conceitos de poder e poder corporativo, mobilizando o enquadramento das Redes Globais de Produção (RGPs) e um conjunto não exaustivo de contribuições-chave para a temática na teoria social e política contemporâneas. $\mathrm{O}$ artigo emprega um modelo teórico-metodológico tridimensional (BACHRACH, BARATZ, 1962; CRENSON, 1971; GAVENTA, 1982; LUKES, 2005) para a investigação do poder como eixo da efetivação da ação econômica.

Empiricamente, o trabalho apresenta os resultados parciais de uma investigação comparativa sobre municípios e corporações mineradoras de ferro em Minas Gerais, abarcando contextos de atividade econômica declinante (Itabira), em expansão (Congonhas) e em implantação (Conceição do Mato Dentro). De um lado, a comparação adota um enfoque sincrônico e uma tipificação segundo diferentes posições no ciclo de extração mineral, tendendo a privilegiar as diferenças entre os casos. De outro, focaliza as modalidades da ação econômica e do poder corporativo exercido pelas companhias mineradoras em situações de interação. ${ }^{2}$

A pesquisa mobilizou técnicas de observação direta, com a participação dos autores em eventos públicos e reuniões comunitárias; assim como entrevistas com roteiro semiestruturado com agentes políticos (representantes do Executivo, do Legislativo e do Ministério Público) e sociais (sindicatos, associações de moradores, movimentos sociais, ONGs, fundações e Igreja Católica) ${ }^{3}$, abrangendo registros em áudio, posteriormente transcritos: quinze em Congonhas, onze em Itabira e oito em Conceição do Mato Dentro, entre 2012 e 2015.

O texto se encontra estruturado em duas seções principais, além desta Introdução e das Considerações finais. Na segunda seção, as noções de poder e poder corporativo em RGPs são

2 A análise mobiliza os padrões de ação economicamente relevante (WEBER, 2003) e as formas coletiva e institucional do poder (HENDERSON et al., 2011) de maneira complementar, renunciando a uma apresentação simétrica dos diferentes agentes não econômicos nos casos investigados.

3 Todos os contatos realizados com representantes das empresas mineradoras não resultaram em entrevistas. 
avaliadas criticamente à luz das contribuições já clássicas a esses temas no âmbito da sociologia e da ciência política. A terceira seção apresenta os estudos de caso. As considerações finais recuperam e sumarizam os resultados da discussão, além de apontar algumas lacunas do debate e futuros desdobramentos.

\section{Enquadrando teoricamente as noções de poder e poder corporativo em RGPs}

Essa seção tem como objetivos a apresentação e discussão crítica dos conceitos de poder e de poder corporativo empregados pela abordagem das Redes Globais de Produção (RGPs), a incorporação da discussão contemporânea sobre o tema no âmbito da teoria sociológica e política e, finalmente, a definição de um enquadramento teórico sintético para a investigação do tema do poder em contextos multiagente. A seção parte do pressuposto de que a "categoria conceitual" poder e suas "formas" específicas (HENDERSON et al., 2011, pp. 157-158) permanecem subdesenvolvidas na literatura das RGPs, apesar de esforços pontuais de aprofundamento (LEVY, 2008; RUTHERFORD, HOLMES, 2008).

Embora o conceito não seja explicitamente formulado, o poder nas RGPs remete à "capacidade de influenciar decisões e alocações de recursos [...] decisiva e consistentemente em seus próprios interesses" (HENDERSON et al., 2011, p. 157). Nesses termos, seu uso se alinha ao debate contemporâneo das ciências sociais, onde poder pode ser definido como "a capacidade de produzir ou contribuir para resultados que afetem significativamente [...] outros" (LUKES, 1996, p. 580).

Entretanto, nessa literatura, o poder corporativo tende a ser atribuído arbitrariamente à firma líder de uma RGP em contextos em que predominam os agentes econômicos. Não obstante, suas concepções de poder coletivo e institucional introduzem uma perspectiva multiagência. Assim, Henderson et al. (2011) atribuem capacidades desiguais de influência a "agentes coletivos" ou sociais (como sindicatos, associações patronais, ONGs, etc.) e a agentes políticos (Estados, organismos multilaterais, etc.) sobre decisões econômicas.

Mais amplamente, o modelo pressupõe que a atividade econômica é desempenhada em contextos interativos caracterizados por agentes diversificados (econômicos, políticos e sociais) dotados de capacidades assimétricas de influência recíproca. A despeito dessa abertura a uma interpretação sociológica dos sistemas transnacionais de produção, dois argumentos críticos principais podem ser formulados quanto à concepção do poder em RGPs.

O primeiro questiona seu componente acionalista. Assim, o poder é concebido como capacidade ou atributo do agente - individual ou coletivo. Mais importante, esse acionalismo é acentuado em razão da indiferença com sua dinâmica; consequentemente, recursos específicos de poder e suas formas de mobilização são negligenciados. 
A segunda alegação diz respeito ao seu elemento interacionista, que prescinde de fatores cognitivos e estruturais ${ }^{4}$ relacionados à inscrição em e à mediação do poder por objetos, instituições e outros fenômenos não redutíveis ao contexto. Desse modo, Clegg e Haugaard (2009, p.3) argumentam que o debate sobre a noção de poder em ciências sociais vem enfatizando "percepções mais sistêmicas, menos específicas quanto ao agente, que veem o poder como constitutivo da [própria] realidade [...]”.

Ademais, as debilidades acionalista e interacionista - recursos e formas do e estruturas de poder, respectivamente - repercutem ainda em uma terceira crítica, relativa à negligência do tema da legitimidade. Dessa forma, a abordagem tanto contorna as formas polares de exercício do poder como autoridade e como coerção, como negligencia suas expressões particulares como consenso, hegemonia, dominação e violência. Assim, acredita-se que uma formulação explícita do conceito no âmbito das RGPs e sua aproximação ao debate nas ciências sociais tende a proporcionar maior apuro conceitual com ênfase nas relações multiagente.

Tomando como base essa representação do campo, esse artigo reforça a filiação prévia à matriz do conflito (RAMALHO et al., 2013). Dessa forma, o argumento segue o influente mapeamento conceitual de Lukes (2005) do tema do poder na ciência política, mobilizando três concepções específicas.

A primeira dimensão de poder enfoca a influência de um agente sobre outro(s) como 'poder sobre', apreendendo o conflito observável como uma espécie de "teste experimental de imputações de poder" (LUKES, 2005, p. 19) a determinados agentes. Nesse sentido, duas objeções-chave podem ser feitas. Em primeiro lugar, o conflito estaria restrito à tomada de decisão política, sendo essa caracterizada por preferências definidas e livre acesso aos diferentes grupos de interesse. Por sua vez, essa concepção privilegia o exercício do poder, em detrimento de sua posse e dos recursos a ela associados. Desse modo, seu "foco sobre o comportamento [dos agentes]" (LUKES, 2005, p. 19) negligencia o enorme potencial de conflito inerente às fases prévias à tomada de decisão.

Assim, a segunda dimensão do poder acresce ao seu exercício observável um elemento específico relacionado à capacidade dos agentes de antepor obstáculos à emergência de questões como problemas públicos (LUKES, 2005). A contribuição seminal de Bachrach e Baratz (1962) pode ser sintetizada no argumento de que os recursos e formas do poder compreendem não apenas a influência de um agente sobre outro(s), mas também a obstrução de sua capacidade para a ação, definida como mobilização de viés.

Lukes (2005), no entanto, questiona o fato de ambas as concepções compartilharem um enfoque centrado no "conflito observável". De modo similar, argumenta que ambas as perspectivas se apoiam ainda em uma noção subjetiva de interesse, visto como "conscientemente articulado e observável" (LUKES, 2005, p. 24).

4 A categoria enraizamento (HENDERSON et al., 2011) foi excluída da discussão apresentada, embora valorize fatores institucionais que matizam o interacionismo do modelo. 
Nesses termos, o autor defende sua própria concepção de poder, apresentada como uma terceira dimensão. Assim, Lukes (2005) sustenta que o poder pode ser acumulado e mobilizado tanto em situações de presença quanto de "ausência de conflito observável efetivo". Consequentemente, situações de "conflito latente" se fundamentam, para o autor, na possibilidade de um agente conceder legitimidade à ação de outro a despeito de seus interesses objetivos. Dessa forma, a contradição potencial entre interesses subjetivos e objetivos dos agentes e, por conseguinte, "a possibilidade de consenso falso ou manipulado" (LUKES, 2005, p. 28) emergem como elementos-chave desta dimensão do poder.

Adotando a posição apresentada, entende-se que investigações empíricas sobre o poder tendem a se beneficiar grandemente da adoção de uma perspectiva tridimensional, capaz de captar as diferentes dimensões nas quais agentes operam e garantem sua influência sobre os demais. Entretanto, tendo em conta que a concepção tridimensional envolve um enquadramento específico à ação social de tipo político, é necessário ampliar sua aplicação a contextos interativos multiagente. Essa possibilidade é oferecida pelos trabalhos de Crenson (1971) e Gaventa (1982).

Crenson (1971) apresenta os resultados de uma investigação sobre as condições políticas de emergência do problema público da poluição do ar e, dentre outros métodos de pesquisa, mobiliza dois estudos de caso de cidades industriais (Gary e East Chicago, Indiana) nos EUA. Sua investigação aponta para a importância dos chamados "não tomadores de decisão", agentes cujo poder reside na "capacidade de evitar a consideração de alguns tipos de problemas" (CRENSON, 1971, p. 21).

O trabalho de Gaventa (1982), por sua vez, oferece uma contribuição ainda mais importante, articulando formas e, principalmente, recursos para o exercício do poder a 'não eventos'. Para o autor, o não evento "envolve adaptações psicológicas à condição de não ter poder" (GAVENTA, 1982, p. 16) experimentada em interações repetidas com agentes poderosos, e especialmente acentuada para grupos desprivilegiados ou vulneráveis. Em síntese, o trabalho apresenta um conjunto de contribuições específicas ao entendimento das fontes e formas do poder. Gaventa (1982) demonstrou a natureza unitária e cumulativa do poder, assim como, diferentemente de Lukes (2005), enfatizou o caráter mutuamente reforçador das três dimensões do poder, apoiando-se na "transferibilidade de seus componentes" (GAVENTA, 1982, p. 252).

Diante dessas possibilidades analíticas, o objetivo da próxima seção é articular a abordagem das três dimensões do poder e os domínios estático (recursos) e dinâmico (exercício) do poder corporativo em três estudos de caso: i. a CSN em Congonhas; ii. a Anglo American em Conceição do Mato Dentro; e iii. a Vale em Itabira. A discussão enfatiza as características dos municípios e das corporações e estratégias em questão, relacionando-os aos agentes políticos e sociais em escala local e aos recursos e formas de exercício do poder corporativo. 


\section{Discutindo o poder corporativo em três contextos}

\section{Congonhas e a $\mathrm{CSN}^{5}$}

Congonhas (MG) se localiza no Quadrilátero Ferrífero (QF) e reúne algumas das principais operações extrativas da região, sediando a sétima maior mina de ferro no Brasil: Casa de Pedra (MINÉRIOS \& MINERALES, 2016). A mina entrou em operação em 1913, tendo sido nacionalizada sob o controle da recém-criada Companhia Siderúrgica Nacional S.A. (CSN), em 1941.

A CSN é uma das maiores siderúrgicas em operação no Brasil, tendo respondido por 12,7\% da produção nacional em 2015 (CSN, 2016, p. 31). O período de boom das commodities (2003-2011) foi decisivo para sua focalização, tendo impulsionado uma convergência das estratégias de investimento e de mercado da corporação para o nodo extrativo de sua rede. Um dos principais movimentos nesse sentido foi a tentativa de conversão da mina Casa de Pedra em eixo da rede de produção da CSN, que atingia a capacidade de extração de $55 \mathrm{Mtpa}$. em 2013. A 'aposta' residia no aumento progressivo dessa capacidade: para $70 \mathrm{Mt}$ pa. em 2014, $89 \mathrm{Mtpa}$. em 2015 e, posteriormente, 100 Mtpa (ALERIGI JR., 2012).

Entretanto, essa pretensão foi desafiada de modo consistente em escala local entre 2007 e $2012^{6}$. Questões relevantes, como a alteração paisagística e a poluição atmosférica passaram a pautar as relações entre mineradoras e os agentes políticos e sociais. Não obstante, o principal tema mobilizado remetia à pressão sobre os recursos hídricos induzida pelo projeto de expansão (SANTOS, 2015a). A disputa material e simbólica assumiu então característica institucionalizada, se centrando na Serra Casa de Pedra, que abriga 29 pontos de captação de água e responde por cerca de 60\% do abastecimento público municipal (MPMG, 2011).

É nesses termos que um conflito observável em âmbito legislativo constituiu uma espécie de "teste experimental" (LUKES, 2005, p. 19) dos recursos e formas de mobilização do poder para os agentes envolvidos. Assim, o flanco da Serra voltado à área urbana tornou-se objeto de tombamento por meio de legislação municipal em 2007 (CÂMARA MUNICIPAL DE CONGONHAS, 2007).

No entanto, a disputa evoluiu imediatamente para a definição de seus limites, atualizando o debate legislativo sob o Projeto de Lei $n^{\circ}$ 027/2008, de iniciativa popular, que versava sobre a delimitação do polígono de tombamento. A CSN, então, contestou o projeto, alegando sua fragilidade técnica, "e contratou uma empresa de consultoria para fazer o levantamento da área" (MPMG, 2011).

5 A discussão da seção se baseia em Ramalho et al. (2013) e Santos (2015a).

6 Apesar dos esforços combinados de agentes políticos relevantes nos governos municipal, estadual e federal, interessados na elevação da arrecadação municipal, na redistribuição territorial dos royalties e na sustentação de uma estratégia de crescimento centrada nas commodities; tais interesses convergiam com os da CSN e demais mineradoras em Congonhas em um coalizão pró-mineral. 
Em 2010, a Câmara Municipal realizou audiência pública para discutir os limites do tombamento (RAMALHO et al., 2013). Além disso, a oposição entre a corporação e grupos de interesse se adensava a partir do ingresso de novos agentes, complexificando o desafio. Assim, a $1^{\text {a }}$ Promotoria de Justiça da Comarca de Congonhas, órgão do Ministério Público de Minas Gerais (MPMG), "instaurou inquérito civil público e requisitou a realização de vistoria e elaboração de um laudo por peritos da Central de Apoio Técnico do Ministério Público" (MPMG, 2011).

Ainda, agentes sociais afetados ou interessados diretamente, tais como a comunidade do Pires e o Grupo Rede Congonhas passaram a atuar na esfera pública de modo a exercer poder coletivo (HENDERSON et al., 2011), mobilizando diretamente o tema do potencial desabastecimento hídrico.

Em paralelo, a ação da $1^{\text {a }}$ Promotoria de Congonhas, a partir de 2008, parece ter conformado as condições-chave para a combinação, ainda que pontual e intermitente, das formas institucional e coletiva de exercício do poder. O nível da Coordenadoria Regional do $\mathrm{MPMG}^{7}$ tornou-se estratégico nas principais ações de contestação às atividades minerárias e a seus agentes em Congonhas. Essa diretriz é ilustrada na emissão do Parecer de Recomendação da Preservação do Morro do Engenho, na Serra Casa de Pedra, encaminhado à Câmara Municipal de Congonhas em 2009 (MPMG, 2011). O documento defendia a "necessidade da delimitação do perímetro de tombamento do monumento Serra da Casa de Pedra dentro dos limites propostos no Projeto de Lei de iniciativa popular no 027/2008” (MPMG, 2011).

Contrariando o parecer, entretanto, a disputa foi resolvida com a aprovação de $85 \%$ da área de tombamento proposta no PL n $\mathrm{n}^{\circ}$ 027/2008, incorporando, dessa forma, uma emenda que liberava $15 \%$ do perímetro do flanco urbano da Serra para estudos geológicos (CÂMARA MUNICIPAL DE CONGONHAS, 2012) e para a expansão da CSN. Sua aprovação e sanção pelo Poder Executivo municipal, em 28 de dezembro de 2012, demonstram que a corporação, embora desafiada consistentemente, pôde mobilizar recursos adicionais exógenos à deliberação pública de tipo pluralista e que, portanto, escapam à concepção da primeira dimensão do poder (LUKES, 2005).

Não obstante, o emprego desses recursos foi necessário exatamente pelas características mais difusas do acúmulo e do exercício do poder em Congonhas. Apesar de seu ingresso longevo, a CSN não é a única mineradora atuando no município ${ }^{8}$, embora seja a mais importante no que concerne às reservas e volume extraído. Nesse sentido, embora os processos de formação socioeconômica de company towns como Gary (CRENSON, 1971), Middlesboro (GAVENTA, 1982) e Volta Redonda (LIMA, 2014), cidade de origem da CSN, possuam semelhanças com o de Congonhas, sua atual morfologia é bastante distinta das de cidades-empresa contemporâneas, como Itabira.

7 O intercâmbio entre a $1^{\text {a }}$ Promotoria e a Coordenadoria Regional tendia a evitar que pressões em escala local afetassem as ações de desafio às mineradoras.

8 Além dela e sua subsidiária Congonhas Minérios, a corporação compartilha esse espaço econômico com a Ferrous Resources do Brasil Ltda., a Ferro Mais Mineração Ltda. e a Vale S.A. 
Nessas condições, populações desprivilegiadas e grupos de interesse dotados de recursoschave e hábeis em mobilizá-los fizeram convergir concepções institucionais e não institucionais de agência, com vistas a contrabalançar o poder corporativo. Em um setor caracterizado pelo imperativo da substituição de reservas (BRIDGE, 2008), formas de desafio consistente ao poder corporativo expressas como contestação às pretensões de ampliação de direitos de propriedade não necessariamente precisam atingir seus objetivos (a conservação da Serra e de seus recursos hídricos) para afetar negativamente a corporação. Nesse caso, a conjunção do ciclo de contestação e do fim do período de preços elevados do minério de ferro impôs severas restrições à estratégia corporativa da CSN.

\section{Conceição do Mato Dentro e a Anglo American ${ }^{9}$}

Conceição do Mato Dentro (MG) é um município de pequeno porte localizado a 160 km de Belo Horizonte, na região da Serra do Espinhaço. A chegada da MMX Mineração e Metálicos S.A. (MMX) em 2006 marcou seu processo de transformação socioeconômica. Após a transferência de seus ativos para a Anglo American Participações em Mineração Ltda. (Anglo American), em 2008, essa transformação se acelerou, com a expansão das operações da mina (MINÉRIOS \& MINERALES, 2016).

A Anglo American foi fundada na África do Sul (1917) para atuar na exploração de ouro e diamantes, tendo chegado ao Brasil em 1973 (ANGLO AMERICAN, 2013). Nos anos 2000, respondendo à elevação drástica da demanda, a corporação aprofundou a diversificação de seu portfólio de investimentos com a aquisição do Projeto Minas-Rio (PMR) ${ }^{10}$. Mais complexo do que previsto, esse movimento induziu o agravamento sistemático dos resultados ${ }^{11}$ da corporação a partir de 2012, momento que marcou o início do período após o boom (SANTOS, 2015b).

O exercício de poder por parte da MMX e da Anglo American esteve fortemente associado a aspectos econômicos e ideológicos. Previsões habituais de geração de trabalho e renda converteram-se em um léxico persuasivo para os agentes políticos, destituídos de experiência prévia com agentes do setor. Nesses termos, observou-se um processo de alinhamento cognitivo entre agentes econômicos e políticos em torno do discurso do crescimento econômico (RIBEIRO, 2008),

Dessa forma, ações institucionais orientadas à simplificação e redução dos custos associados à desapropriação de áreas necessárias ao PMR passaram a ser implementadas. Enquanto o PMR era incluído no Regime Especial de Incentivos para o Desenvolvimento da Infraestrutura (TOMAZ, 2011), o Governo do Estado de Minas Gerais declarava a utilidade

9 A discussão dessa seção se baseia em Milanez e Santos (no prelo) e Santos e Milanez (2015c).

10 O PMR compreende a mina (26 Mtpa.), um mineroduto e um porto (100 Mtpa.).

$11 \mathrm{O}$ desempenho do PMR impactou negativamente a subsidiária brasileira (que teve três presidentes em 13 meses) e o grupo como um todo. O projeto, após atraso de cinco anos, precisou de investimentos adicionais de cerca de US\$ 4 bilhões (AGOSTINI, 2009; ANTONIOLI, 2014). 
pública das propriedades necessárias para a implantação do projeto (BECKER, PEREIRA, 2011). Essa convergência de interesses foi reforçada ${ }^{12}$ pelo uso da tática da "porta-giratória", isto é, pela mobilidade de profissionais de empresas privadas para cargos públicos (ARELLANOYANGUAS, 2016). Em 2013, a Anglo American contratou como Gerente de Licenciamento o funcionário que, até o ano anterior, era Superintendente de Regularização da Secretaria de Estado de Meio Ambiente e Desenvolvimento Sustentável, e um dos responsáveis pelo processo de licenciamento do PMR (CIMOS, 2013).

Não obstante, o processo de licenciamento ambiental do PMR sintetizou, em alguma medida, os recursos e formas de exercício do poder corporativo no município. Assim, foi por meio desse conjunto institucionalizado de procedimentos que, sucessivamente, MMX e Anglo American canalizaram e selecionaram demandas específicas passíveis de reconhecimento como problemas públicos, enquanto excluíam outras como não problemas (CRENSON, 1971).

Dessa forma, a definição da população atingida representou uma fonte importante de conflito. A definição de três "núcleos populacionais" na Área de Influência Direta do Projeto no Estudo de Impacto Ambiental (EIA) contratado pela MMX (BRANDT MEIO AMBIENTE, 2007) levou a forte questionamento dos movimentos locais (SISEMA, 2008). Embora o novo estudo tenha identificado 22 comunidades afetadas (DIVERSUS AMBIENTE E CULTURA, 2014), muitas permaneceram excluídas (GESTA/UFMG, 2014).

A fragmentação do licenciamento do PMR assumiu natureza modelar. Apesar de consistir em um sistema interligado, suas infraestruturas foram licenciadas independentemente: mina e porto pelos governos de Minas Gerais e Rio de Janeiro, respectivamente, e mineroduto pelo Governo Federal. Essa tática facilitou consideravelmente o licenciamento, uma vez que ocultou os impactos cumulativos e enfraqueceu a potencial articulação dos movimentos sociais críticos (BARCELOS, 2013).

A tática permitiu à corporação transitar entre as fronteiras da alegalidade e da ilegalidade, postergando o enfrentamento das questões críticas. Desse modo, a Anglo American conseguiu mantê-las sob a condição de não problemas públicos que demandam soluções imediatas, exercendo seu poder corporativo sobre os demais agentes como mobilização de viés, no sentido atribuído por Bachrach e Baratz (1962).

Ademais, táticas divisivas dos grupos de interesse potencialmente críticos ao PMR tornaram-se um elemento-chave desde o início das operações da MMX. Assim, enquanto um movimento de contestação social se estruturava nas áreas rurais do município a partir de experiências concretas com a corporação e suas subcontratadas no acesso a e na aquisição de terras (ATINGIDO A, 2014), a corporação mobilizava um discurso de geração, direta e indireta, de empregos e renda em sua área urbana. A polarização de interesses já existente se apoiou

12 Ademais, práticas ilegais, como a corrupção de funcionários governamentais, têm sido registradas nas relações de empresas do setor, incluindo a MMX, com agentes políticos envolvidos no processo de licenciamento ambiental no estado de Minas Gerais (G1, 2014). 
na deficiência dos meios de comunicação disponíveis e na construção de uma interpretação 'monopólica' (GAVENTA, 1982, pp. 105-106) dos impactos do PMR.

Paralelamente às táticas de mobilização de viés e gestão antecipatória da emergência de temas potencialmente 'perigosos', o exercício do poder corporativo da Anglo American incorporou ainda práticas de violência física e simbólica. Assim, foram empregadas táticas de "encurralamento" dos residentes rurais resistentes aos acordos de aquisição de terras (ATINGIDO A, 2014). Tais práticas se combinaram a formas de intimidação e ameaça e ao uso de violência perpetradas diretamente por funcionários da Anglo American, assim como indiretamente, por indivíduos e empresas a ela relacionados (ALMG, 2013; ATINGIDO B, 2014).

\section{Itabira e a Vale ${ }^{13}$}

Itabira (MG) é uma cidade de médio porte também localizada no Quadrilátero Ferrífero. Suas reservas de minério de ferro se tornaram conhecidas mundialmente em 1910, quando os direitos de lavra foram adquiridos pela firma britânica Brazilian Hematite Syndicate (BHS), mais tarde Itabira Iron Ore Company (IIOC). Durante a $2^{\text {a }}$ Guerra Mundial emergiria um cenário oportuno ao aproveitamento das jazidas, com a assinatura dos Acordos de Washington em 1942 por Brasil, EUA e Reino Unido. Os acordos previam financiamento e apoio técnico para implementação da infraestrutura de exploração e logística, transferência dos ativos da IIOC ao governo brasileiro e fornecimento do minério aos Aliados (TRINER, 2011).

Os acordos deram origem à Companhia Vale do Rio Doce (CVRD) em 1942 e a um padrão operacional tipicamente exportador na extração de ferro no Brasil (SILVA, 2004; TRINER, 2011; VALE, 2012). A CVRD foi privatizada em 1997 e mudou sua denominação comercial para Vale S.A. em 2007. Em 2015, a corporação era a oitava maior mineradora do mundo em relação à capitalização de mercado $(\mathrm{PwC}, 2016)$ e a maior produtora de minério de ferro (Vale, 2016).

No que diz respeito à força de trabalho, o Sindicato Metabase de Itabira e Região é o representante de quase 5.500 trabalhadores ativos e aposentados na região (DIÁRIO DE ITABIRA, 2015b). A história desse sindicato tem sido caracterizada pelo caráter episódico do desafio aberto à Vale, sendo sua constituição atribuída à estratégia de relações de trabalho da então CVRD, voltada à necessidade de controle dos trabalhadores na localidade, que emergiu após a primeira greve em 1945 (MINAYO, 2004).

Desde então, ações de desafio ao poder corporativo no município parecem emergir apenas em situações de crise aguda. Assim, uma segunda mobilização aconteceu na transição para os anos 1990, motivada por perdas salariais em um contexto inflacionário (DIÁRIO DE ITABIRA, 2015b) e pelas expectativas de redução da força de trabalho relacionadas ao processo de privatização (CARVALHO, 2014). A terceira greve ocorreria em 2008; a retração na demanda 
derivada da crise econômica mundial motivou a proposta de suspensão de todos os contratos por seis meses e provocou a demissão de 1,5 mil trabalhadores em Itabira (SANTOS, MILANEZ, 2015b). Uma nova onda de contestação ocorreu em 2015, quando a Vale planejava demitir um número significativo de seus trabalhadores na cidade (DIÁRIO DE ITABIRA, 2015a).

A descrição desses episódios evoca um questionamento acerca da natureza da aquiescência dos trabalhadores de Itabira, nos termos propostos por Gaventa (1982). Assim, a opinião de um trabalhador da corporação ligado à Oposição Sindical tende a reforçar uma interpretação da ação coletiva em termos de relativa impotência diante do poder corporativo: "Por Itabira ser uma cidade monoindustrial, né?! É só a Vale que predomina. [...] Hoje outras mineradoras tão crescendo, né?! Naquele período, não. Era só a Vale mesmo e se saísse da Vale era... lavar carro, né?!” (TRABALHADOR 1, 2015).

Como o entrevistado deixa entrever, a dependência dos empregos e "a ameaça de perdêlos" (GAVENTA, 1982, p. 87), assim como da 'desclassificação social' daí derivada, constitui um elemento crítico da aceitação individual das condições de vida e trabalho conformadas pela mineradora.

No entanto, a morfologia da company town (LIMA, 2014) condiciona as relações também em sua dimensão coletiva. Assim, um padrão de "dependência social e econômica" (GAVENTA, 1982, p. 161) complementar pode ser identificado no mercado de trabalho local ${ }^{14}$. Entre 2010 e 2015, a Indústria Extrativa Mineral (IEM) foi responsável por 28-37\% dos empregos formais disponíveis em Itabira $^{15}$ (MTE, 2017). Se a dinâmica da ação coletiva de tipo sindical e do desafio ao poder corporativo é episódica, ela responde, em certa medida, à configuração social e econômica dependente que constitui uma das características da cidade-empresa.

Desse modo, como aponta Gaventa (1982), a presença de um agente econômico que exerceu ação criadora e/ou transformadora - no caso de Itabira - sobre uma dada estrutura socioeconômica, induz "resposta[s] adaptativa[s]" (GAVENTA, 1982, p. 16) dos agentes individuais e coletivos às condições de destituição relativa de poder e às situações repetidas de fracasso em erigir desafios consistentes ao poder corporativo. A capacidade de definir o acesso ao trabalho e, consequentemente, à "inscrição na estrutura social” (CASTEL, 1998, p. 34) na cidade mineradora aumentam consideravelmente o poder corporativo da Vale: “[...] as pessoas [...] foram criadas com um nível [...] de dominação tão grande... Elas dizem: 'Mexer com a Vale não... meu filho um dia pode trabalhar lá. [...] Por isso a cidade não grita” (TRABALHADOR 1, 2015).

14 Um padrão correspondente é observável no que respeita à formação das receitas públicas. As receitas estadual e municipal são fortemente dependentes do desempenho econômico da IEM, particularmente devido ao pagamento de royalties. Em 2016, a Vale e suas subsidiárias foram responsáveis por 66\% dos € 222,7 milhões arrecadados pelo estado (DNPM, 2016). Em Itabira, em 2014, os royalties recebidos, € 19,4 milhões, equivaleram a $11 \%$ da receita municipal total.

15 Esses dados se referem exclusivamente aos trabalhadores diretos de empresas da IEM, em detrimento dos indiretos, classificados no setor de serviços. 
Essa possibilidade se acentua no contexto de um brownfield minerador cujas reservas vêm se esgotando; a mina principal, Cauê, inaugurada em 1942, já foi exaurida, as minas do Meio e cava de Conceição têm previsão de exaustão para 2022 e 2025, respectivamente (SANTOS, MILANEZ, 2015b). Nesses termos, a corporação tem sido hábil em mobilizar receio e esperanças individuais e coletivas em escala local.

O principal recurso mobilizado pela corporação articula a tecnologia para processamento de itabiritos de baixo teor - que prorrogaria a "vida útil" das operações extrativas no município (SANTOS, MILANEZ, 2015b). Isso geraria uma representação discursiva da relação entre cidade e empresa como simbiose e da mineração como "sustentável" temporalmente. Desse modo, agentes coletivos potencialmente desafiadores têm aderido às práticas discursivas mobilizadas pelo agente econômico matricial para descrever sua estratégia de investimento corrente.

Em um plano mais geral, a ausência do desafio ao poder corporativo repousa na concentração de recursos de poder e na possibilidade de exercício unitário do poder corporativo (GAVENTA, 1982) pela Vale. Nesse sentido, focalizar a temática do ambiente permite uma interpretação interativa do exercício do poder por parte da corporação. Sendo a IEM frequentemente responsável por conflitos e impactos socioambientais e a Vale partícipe de alguns dos mais importantes deles no Brasil, é necessário enfocar suas operações em Itabira dessa perspectiva.

A emergência da questão ambiental como problema público em Itabira se assemelha à trajetória do tema na descrição de Crenson (1971) para a cidade de Gary. A ausência de qualquer legislação ambiental em vigor nos anos 1940 e a definição de procedimentos para estudos de impacto ambiental (EIA) pelo Conselho Nacional do Meio Ambiente (CONAMA) apenas em 1986 fizeram do ambiente um "não problema” em Itabira por cerca de quarenta anos.

Não obstante, em meados dos anos 1980, a temática do ambiente começou a ser mobilizada de modo mais incisivo. Assim, em 1984, foi estabelecido o Conselho Municipal de Proteção Ambiental (CODEMA); em 1986, foi instituída uma primeira ação civil pública contra a corporação; e uma segunda apareceria em 1992 (SOUZA, SOUZA e SILVA, 2002).

Entretanto, confirmando a reduzida propensão à contestação por parte dos agentes políticos e sociais de Itabira, as pressões emergentes tinham origem extra-local, sendo lideradas pela FEAM e voltadas à adequação dos agentes econômicos do setor em todo o QF (SANTOS, MILANEZ, 2015b). Como na questão do trabalho, o processo de privatização proporcionou um contexto oportuno para a evolução do desafio ao poder corporativo da Vale. Assim, o Governo do Estado de Minas Gerais exigiu que a Vale apresentasse seu EIA em 1994. A corporação só obteria sua Licença Ambiental Corretiva (LOC) em 2000, que foi condicionada a 54 iniciativas de controle operacional, reabilitação de áreas e compensação ambiental (VALE, 2012).

O processo de adequação ambiental da Vale teria provocado uma mudança efetiva em suas operações, como sugere a maior parte das entrevistas realizadas. No entanto, a despeito do "consenso" aparente, alguns poucos entrevistados se posicionaram de modo diverso quanto ao 
cumprimento das condicionantes da LOC por parte da Vale. De fato, ainda havia disputas pouco aparentes acerca da questão.

Uma avaliação geral das posições em torno da questão do cumprimento das condicionantes da LOC aponta a existência de obstáculos consideráveis à formulação de críticas dirigidas diretamente à corporação. Dessa forma, no âmbito da discussão ambiental, os recursos disponíveis e as formas de exercício do poder por parte da corporação tendem a combinar a adesão ideológica (ou o não desafio) à capacidade de sustentar uma representação do problema da adequação ambiental como "solucionada", em detrimento dos escassos discursos discordantes.

\section{Considerações finais}

A discussão proposta a partir da comparação (Quadro 1) entre os três casos investigados levanta um conjunto de argumentos que possui potencial tanto para enriquecer a discussão sobre o poder nas ciências sociais, quanto para "sociologizar" o debate sobre sistemas transnacionais de produção e sua expressão na literatura das RGPs.

Em Congonhas, as pretensões de expansão da atividade econômica em um contexto brownfield impulsionaram uma forma de desafio à CSN que combinou recursos institucionais e não institucionais e mobilizou agentes diversos de forma articulada nos planos legislativo e extralegislativo. O próprio exercício do poder corporativo pela CSN demonstrou a incompletude da visão unidimensional, mobilizando recursos exógenos à competição política diante da constância do desafio.

Diferentemente, o caso de Conceição do Mato Dentro demonstrou a centralidade da dimensão institucional, com foco no licenciamento ambiental, no processo de seleção e adiamento de problemas e da exclusão de questões como "não problemas", corroborando a relevância de uma interpretação em termos da segunda dimensão do poder. Em um contexto greenfield, a Anglo American mobilizou recursos extrainstitucionais e construiu uma interpretação controlada e "monopólica" dos impactos do PMR, cuja pretensão de autoridade se efetivou e contribuiu para restringir o exercício das formas institucional e coletiva de poder.

Finalmente, a combinação entre a condição de company town e o fim de ciclo mineral em Itabira permitiram à Vale exercer uma modalidade unitária de poder corporativo, tanto condicionando a (não) emergência de problemas públicos (segunda dimensão do poder) - em particular, o ambiental -, quanto estendendo sua influência a uma dimensão interna, capaz de mobilizar subjetivamente a adesão de agentes individuais e coletivos (terceira dimensão) no município. A adesão em questão remete à combinação contraditória entre concessão de legitimidade a agentes poderosos e oposição aos interesses objetivos de uma coletividade. Nesses termos, a Vale foi bem sucedida em sustentar um regime de consenso manipulado (LUKES, 2005) desfavorável à contestação, predominantemente episódica e/ou derivada de fontes extralocais. 
De modo geral, os três casos tematizam a relevância de um entendimento do poder que articula fontes (recursos) e formas (exercício), sem subsumi-los, e sem recair em interpretações centradas em atributos e/ou agentes - poderosos e sem poder. Nesses termos, o poder é entendido de modo propriamente relacional, demandando a mobilização efetiva de recursos em contextos interativos. Desse modo, em situações fundamentalmente assimétricas e povoadas por agentes diversificados, o emprego da matriz do conflito ou do "poder sobre" (CLEGG, HAUGAARD, 2009) permitiu uma compreensão relacional dos contextos socioeconômicos em questão.

Ademais, os casos ilustraram certas deficiências de abordagens interacionistas, que caracterizam em parte o modelo das RGPs, demandando complementos importantes de aportes cognitivo e estruturalista. Dessa maneira, a discussão proposta permitiu combinar os domínios da legitimidade e da ilegitimidade das fontes e formas de poder, integrando as modalidades de contestação consistente e impedida e do consenso manipulado (Lukes, 2005) em uma compreensão da natureza persistente e cumulativa das relações e posições de poder.

No campo das ciências sociais, a investigação de contextos empíricos do tipo apresentado coloca em questão a necessidade de formulações teóricas mais complexas e essencialmente multiagente, como as apresentadas por Crenson (1971) e Gaventa (1982). Espera-se ter contribuído para uma análise desse gênero.

Adicionalmente, variáveis contextuais como o intervencionismo estatal - na conformação de Congonhas e Itabira - e a morfologia socioeconômica na "origem" - monocorporativa ou não - e no "destino" também se mostraram explicativas das trajetórias territoriais investigadas. Assim, a interpretação dos casos a partir das noções de brownfield (Congonhas e Itabira) e de greenfield (Conceição do Mato Dentro) - vinculadas, em sua origem, às condições de recuperação ambiental de áreas industriais degradadas (planejamento urbano) e à estratégia corporativa (administração), respectivamente - evidenciou a diversidade de formas da dependência de recursos por parte das mineradoras. Nessa dimensão, as relações entre agentes econômicos e não econômicos nos três casos se diferenciaram em função de sua interação diacrônica e das estruturas socioeconômicas nas quais se inseriam, conformando as condições do exercício do poder corporativo no sentido: i. do controle da propriedade da terra e da exclusão de reivindicações concorrentes, em Conceição do Mato Dentro; do enfrentamento aos movimentos sociais e da demanda pela preservação dos recursos hídricos, em Congonhas; e da "monopolização" das oportunidades de trabalho e mobilidade social, em Itabira.

No que respeita à abordagem das RGPs e à discussão dos sistemas transnacionais de produção, acredita-se que a formulação tridimensional do poder e sua aplicação às fontes e formas do poder corporativo possam fundamentar uma discussão sociológica das relações entre agentes econômicos e não econômicos - hoje, tipicamente enquadrada como "coordenação" e limitada à eficiência da rede e da ação econômica.

Quanto à especificidade das RGPs minerais (BRIDGE, 2008; SANTOS, MILANEZ, 2015a), admite-se que sua natureza contestável se vincule a três fatores-chave: i. à dimensão não 
renovável e ao volume de extração dos bens minerais, com efeitos de incompatibilidade frente às demandas por terra e por água, principalmente; ii. à natureza da atividade (capital intensiva) e do produto (bem de produção), impactando as condições de ativismo sindical e do consumidor; e iii. ao padrão de dependência econômica local e sua natureza estratégica, induzindo ativismo estatal voltado à diversificação e ao nacionalismo de recursos, respectivamente. Desse modo, as formas corporativa, coletiva e institucional do poder na IEM diferem, em traços gerais, dos padrões exibidos em outras atividades. Não obstante, investigações comparativas intersetoriais a esse respeito têm sido pouco exploradas.

Especificamente, a discussão apresentada ainda demanda a incorporação de aportes específicos sobre o tema do poder corporativo na sociologia econômica, assim como não foi capaz, nesse momento, de tratar das formas institucional e coletiva do poder de maneira comparável. Dessa forma, a perspectiva da inclusão desses tópicos e da ampliação da discussão para os processos relacionados ao valor e ao enraizamento permanecem como temas-chave para investigação futura.

Quadro 1 - Síntese comparada dos resultados

\begin{tabular}{|c|c|c|c|}
\hline Dimensões & CSN / Congonhas & AA / CMD & Vale / Itabira \\
\hline contexto & $\begin{array}{l}\text {-pluricorporativo } \\
\text {-brownfield em expansão }\end{array}$ & $\begin{array}{l}\text {-monocorporativo } \\
\text {-greenfield }\end{array}$ & $\begin{array}{l}\text {-monocorporativo (company } \\
\text { town) } \\
\text {-brownfield em fim de ciclo }\end{array}$ \\
\hline Foco & $\begin{array}{l}\text {-abastecimento hídrico } \\
\text {-mina x serra }\end{array}$ & $\begin{array}{l}\text {-aquisição de terra } \\
\text {-mina x formas de } \\
\text { reprodução social rurais }\end{array}$ & $\begin{array}{l}\text {-empregos } \\
\text {-impactos ambientais } \\
\text {-mina x formas de reprodução } \\
\text { mineradoras }\end{array}$ \\
\hline $\begin{array}{l}\text { natureza / } \\
\text { escala }\end{array}$ & $\begin{array}{l}\text {-desafio consistente em } \\
\text { escala local }\end{array}$ & $\begin{array}{l}\text {-desafio insipiente restrito à } \\
\text { esfera rural }\end{array}$ & $\begin{array}{l}\text {-regime de consenso, com } \\
\text { desafio de tipo episódico e } \\
\text { extralocal }\end{array}$ \\
\hline Plano & $\begin{array}{l}\text { predomínio institucional } \\
\text { (Legislativo e MP) } \\
\text { extrainstitucional }\end{array}$ & $\begin{array}{l}\text { predomínio } \\
\text { extrainstitucional } \\
\text { institucional (Executivo) }\end{array}$ & $\begin{array}{l}\text { predomínio extrainstitucional } \\
\text { institucional (MP) }\end{array}$ \\
\hline Tipos & $\begin{array}{l}\text {-predomínio dos tipos } \\
\text { institucional e coletivo } \\
\text {-subordinação do tipo } \\
\text { corporativo }\end{array}$ & $\begin{array}{l}\text {-predomínio do tipo } \\
\text { corporativo, em coalizão } \\
\text { com institucional } \\
\text {-subordinação do tipo } \\
\text { coletivo }\end{array}$ & $\begin{array}{l}\text {-hegemonia do tipo } \\
\text { corporativo, com } \\
\text { consentimento do tipo } \\
\text { institucional } \\
\text { - virtual ausência do tipo } \\
\text { coletivo }\end{array}$ \\
\hline
\end{tabular}




\begin{tabular}{|c|c|c|c|}
\hline \multirow{5}{*}{ recursos } & -legislativos (leis, AP) & \multirow{5}{*}{$\begin{array}{l}\text {-discursivos (crescimento) } \\
\text {-institucionais (terra) } \\
\text {-não tomada de decisão } \\
\text { (contenção dos conflitos } \\
\text { fundiários/ implante) }\end{array}$} & \multirow{4}{*}{$\begin{array}{l}\text {-discursivos } \\
\text {-não institucionais (exercício } \\
\text { unitário do poder) }\end{array}$} \\
\hline & -jurídicos (inquérito & & \\
\hline & civil público, AP, ACPs, & & \\
\hline & & & \\
\hline & $\begin{array}{l}\text {-não institucionais } \\
\text { (ocupações, captura } \\
\text { corporativa) }\end{array}$ & & $\begin{array}{l}\text {-institucional-jurídicas (ACPs, } \\
\text { LOC) }\end{array}$ \\
\hline resultados & $\begin{array}{l}\text {-efetivação tardia dos } \\
\text { objetivos da CSN, com } \\
\text { resultados econômicos } \\
\text { negativos e redução do } \\
\text { poder corporativo }\end{array}$ & $\begin{array}{l}\text {-efetivação dos objetivos } \\
\text { da AA, com resultados } \\
\text { econômicos negativos e } \\
\text { manutenção do poder } \\
\text { corporativo }\end{array}$ & $\begin{array}{l}\text {-efetivação dos objetivos } \\
\text { da Vale, com resultados } \\
\text { econômicos positivos e reforço } \\
\text { do poder corporativo }\end{array}$ \\
\hline & $\begin{array}{l}\text {-acúmulo e exercício do } \\
\text { poder difusos }\end{array}$ & \multirow{2}{*}{$\begin{array}{l}\text {-poder centralizado } \\
\text {-ineficácia da implantação } \\
\text { do PMR } \\
\text {-fim do boom }\end{array}$} & $\begin{array}{l}\text {-poder extremamente } \\
\text { centralizado }\end{array}$ \\
\hline explicação & $\begin{array}{l}\text {-conjunção do ciclo de } \\
\text { contestação com fim do } \\
\text { boom }\end{array}$ & & $\begin{array}{l}\text {-adaptação individual e } \\
\text { coletiva a situações repetidas } \\
\text { de fracasso }\end{array}$ \\
\hline
\end{tabular}

Fonte: elaboração dos autores.

\section{Referências}

AGOSTINI, Renata. No papel parecia fácil. Revista Exame, 12 nov. 2009. Disponível em: < http://exame.abril.com. br/revista-exame/edicoes/956/noticias/papel-parecia-facil-511296 >. Acesso em: 29 jul. 2016.

ALERIGI JR., Alberto. MG volta a discutir mina da CSN na próxima semana. Reuters Brasil, 01 fev. 2012. Disponível em: < http://br.reuters.com/article/idBRSPE81007C20120201 >. Acesso em: 10 out. 2017.

ALMG. Transcrição da $17^{\mathrm{a}}$ Reunião Extraordinária da Comissão de Direitos Humanos. GERAIS, A. L. D. M. Belo Horizonte 2013.

ANGLO AMERICAN. Annual report 2012. Anglo American plc. London. 2013

ANTONIOLI, Silvia. Anglo American embarca $1^{\circ}$ carregamento de minério de ferro do projeto Minas-Rio. Reuters, 27 out. 2014. Disponível em: < http://br.reuters.com/article/businessNews/idBRKBN0IG0ZS20141027 >. Acesso em: 29 jul. 2016.

ARELLANO-YANGUAS, Javier. Mining policies in Humala's Peru. In: HASLAM, P. A. e HEIDRICH, P. (Ed.). The political economy of natural resources and development: from neoliberalism to resource nationalism. New York: Routledge, 2016, p.173-190.

ATINGIDO A. Entrevista com Atingido pelo Projeto Minas-Rio. MILANEZ, B. e SANTOS, R. S. P. D. Belo Horizonte, 2014.

ATINGIDO B. Entrevista com Atingido pelo Projeto Minas-Rio. MILANEZ, B. Conceição do Mato Dentro, 2014.

BACHRACH, Peter; BARATZ, Morton S. Two faces of power. American Political Science Review, v. 56, n. 4, p. 947-952, 1962.

BARCELOS, Eduardo. O projeto Minas Rio e seus impactos socioambientais: olhares desde a perspectiva dos atingidos. Rio de Janeiro: Instituto Brasileiro de Pesquisa Socio Econômica, 2013. 
BECKER, Luzia Costa; PEREIRA, Denise Castro. O projeto Minas-Rio e o desafio do desenvolvimento territorial integrado e sustentado: a grande mina em Conceição do Mato Dentro. In: FERNANDES, F. R. C.;ENRÍQUEZ, M. A. R. S., et al (Ed.). Recursos Minerais \& Sustentabilidade Territorial. V. 1 Grandes Minas. Rio de Janeiro: CETEM/MCTI, 2011, p.229-258.

BRANDT MEIO AMBIENTE. Estudo de impacto ambiental: lavra a céu aberto para produção de 56 milhões de toneladas por ano, tratamento de minério de ferro e infra-estrutura de produção. Brandt Meio Ambiente. Nova Lima, 2007.

BRIDGE, Gavin. Global production networks and the extractive sector: governing resource-based development. Journal of Economic Geography, v. 8, n. 3, p. 389-419, 2008.

CÂMARA MUNICIPAL DE CONGONHAS. Lei n. 2.694, de 2 de maio de 2007. Dispõe sobre o tombamento do conjunto paisagístico da serra "Casa de Pedra” e dá outras providências. CÂMARA MUNICIPAL DE CONGONHAS. Congonhas. 2694, 2007.

. Lei n. 3.224, de 28 de dezembro de 2012. Dispõe sobre o espaço territorial tombado, denominado Conjunto de Serras Casa de Pedra. CÂMARA MUNICIPAL DE CONGONHAS. Congonhas. 3224, 2012.

CARVALHO, Laura Nazaré de. Análise da ação dos sindicatos dos trabalhadores da mineradora Vale SA na região Sudeste brasileira. Textos e Debates, v. 1, n. 23, p. 91-114, 2014.

CASTEL, Robert. As Metamorfoses da Questão Social: uma crônica do salário. Vozes: Petrópolis, 1998.

CIMOS. Ata da 8a. Reunião Pública da Reasa, 18 de fevereiro de 2013. Coordenadoria de Inclusão e Mobilização Sociais, Ministério Público de Minas Gerais. Belo Horizonte, 2013.

CLEGG, Stewart R.; HAUGAARD, Mark. Introduction: why power is the central concept of the social sciences. In: CLEGG, S. R. e HAUGAARD, M. (Ed.). The Sage Handbook of Power. London: Sage, 2009, p.1-24.

CRENSON, Matthew A. The Un-politics of Air Pollution: a study of non-decision-making in the cities. Baltimore: Johns Hopkins Press, 1971.

CSN. Form 20-F. NYSE. New York, 314 p. 2016

DIÁRIO DE ITABIRA. Metabase faz protesto na porta da Câmara. Diário de Itabira, Itabira, 2015a. Sete Décadas de Conquistas Históricas. Diário de Itabira, Itabira, p.1-8, $2015 \mathrm{~b}$.

DIVERSUS AMBIENTE E CULTURA. Estudo de definição sobre comunidades/famílias a serem reassentadas. Mimeo. Belo Horizonte, 2014.

DNPM. Maiores arrecadadores CFEM: Departamento Nacional de Produção Mineral. 2016.

G1. MP denuncia secretário estadual de Meio Ambiente da gestão Anastasia. G1 Minas Gerais, 05 jun. 2014. Disponível em: < http://g1.globo.com/minas-gerais/noticia/2014/06/mp-denuncia-secretario-estadual-de-meio-ambiente-da-gestao-anastasia.html >. Acesso em: 02 ago. 2016.

GAVENTA, John. Power and powerlessness: quiescence and rebellion in an Appalachian valley. Urbana: University of Illinois Press, 1982.

GESTA/UFMG. GESTA/UFMG. A uma semana das eleições, Anglo manda e governo de Minas obedece. Grupo em Estudos e Temáticas Ambientais, Universidade Federal de Minas Gerais, 30 set. 2014. Disponível em: < http://conflitosambientaismg.lcc.ufmg.br/noticias/a-uma-semana-das-eleicoes-anglo-manda-e-governo-de-minas-obedece/ >. Acesso em: 28 jna. 2015.

HENDERSON, Jeffrey et al. Redes de produção globais e a análise do desenvolvimento econômico. Revista Pós Ciências Sociais, v. 9, n. 15, p. 143-140, 2011.

LEVY, David. Political contestation in Global Production Networks. Academy of Management Review, v. 33, n. 4, p. $943-963,2008$. 
LIMA, Raphael Jonathas da Costa CSN e Volta Redonda: uma relação histórica de dependência e controle. Política \& Sociedade, v. 12, n. 25, p. 41-64, 2014.

LUKES, Steven. Poder. In: OUTHWAITE, W. e BOTTOMORE, T. (Ed.). Dicionário do Pensamento Social do Século XX. Rio de Janeiro: Jorge Zahar Editor, 1996, p. 580-582.

Power: a radical view. 2nd. Basingstoke, 2005.

MILANEZ, Bruno; SANTOS, Rodrigo Salles Pereira dos. L’exploitation minière, la stratégie d'entreprise et la flexibilisation de la réglementation environnementale au Brésil: le cas du Projet Minas-Rio. Brésil(s), no prelo.

MINAYO, Maria Cecília de Souza. De Ferro e Flexíveis: marcas do Estado empresário e da privatização na subjetividade operária. Rio de Janeiro: Garamond, 2004.

MINÉRIOS \& MINERALES. Ranking por Substância - Produção Anual em Toneladas (ROM) 2015. Minérios \& Minerales. São Paulo. XL: p. 14-18, 2016.

MPMG. MPE recomenda proteção da Serra Casa de Pedra, em Congonhas. Ministério Público do Estado de Minas Gerais, 09 mai. 2011. Disponível em: < http://www-antigo.mpmg.mp.br/portal/public/noticia/index/id/24769 >. Acesso em: 10 out. 2017.

MTE. Relação Anual de Informações Sociais: Secretaria de Políticas Públicas de Emprego. 2017.

PWC. Mine 2016: slower, lower, weaker... but not defeated. PricewaterhouseCoopers, Canada. Toronto. 2016. RAMALHO, José Ricardo; SANTOS, Rodrigo Salles Pereira dos; LIMA, Raphael Jonathas da Costa Estratégias de desenvolvimento industrial e dinâmicas territoriais de contestação social e confronto político. Sociologia\&Antropologia, v. 3, n. 5, p. 175-200, 2013.

RIBEIRO, Gustavo Lins. Poder, redes e ideologia no campo do desenvolvimento. Novos Estudos-CEBRAP, n. 80, p. 109-125, 2008.

RUTHERFORD, Tod; HOLMES, John. 'The flea on the tail of the dog': power in global production networks and the restructuring of Canadian automotive clusters. Journal of Economic Geography, v. 8, n. 4, p. 519-544, 2008. SANTOS, Rodrigo Salles Pereira dos. Da Estratégia Corporativa à Ação Economicamente Relevante: a CSN e a contestação social na mineração de ferro. Revista Pós Ciências Sociais, v. 12, n. 24, p. 143-166, 2015 a.

Mineração e a conjuntura do pós-boom das commodities. Audiência Pública da Comissão Especial - PL 37/11, Brasília, 2015b. Disponível em: < http://www.uff.br/poemas/files/2015/09/Santos-2015-Minera\%C3\%A7\%C3\%A3o-e-a-Conjuntura-do-P\%C3\%B3s-Boom-das-Commodities.pdf >. Acesso em: 10 out. 2017.

SANTOS, Rodrigo Salles Pereira dos; MILANEZ, Bruno. The Global Production Network for iron ore: Materiality, corporate strategies, and social contestation in Brazil. The Extractive Industries and Society, v. 2, n. 4, p. 756-765, $2015 a$.

Redes Globais de Produção (RGPS) e Conflito Socioambiental: a Vale S.A. e o Complexo Minerário de Itabira. In: VII Simpósio Internacional de Geografia Agrária, Goiânia. Anais SINGA. p. 2093-2108.

A RGP da Anglo American e Conflitos Socioambientais na Mineração de Ferro: valor, poder e enraizamento no Projeto Minas-Rio. In: 39 Encontro da ANPOCS, Caxambu. Anais ANPOCS.

SILVA, Marta Zorzal. A Vale do Rio Doce na estratégia do desenvolvimentismo brasileiro. Vitória: EDUFES, 2004.

SISEMA. Anglo Ferrous Minas-Rio Mineração S.A - Parecer único SISEMA no. 001/2008. Sistema Estadual de Meio Ambiente de Minas Gerais. Diamantina, 2008.

SOUZA, M. R. G. de; SOUZA E SILVA, M. G. S. Itabira - vulnerabilidade ambiental: impactos e riscos socioambientais advindos da mineração em área urbana. In: XIII Encontro da Associação Brasileira de Estudos Populacionais (ABEP), Ouro Preto. Anais, p. 1-17, 2002. 
TOMAZ, Rafael. Projeto Minas-Rio foi incluído no programa REIDI. Diário do Comércio, 08 jan. 2011. Disponível em: < http://www.diariodocomercio.com.br/noticia.php?id=48024 >. Acesso em: 02 ago. 2016.

TRABALHADOR 1. Entrevista com integrante da Oposição Sindical. MILANEZ, B. e SANTOS, R. S. P. D. Itabira, 2015.

TRINER, Gail D. Mining and the state in Brazilian development. London: Pickering \& Chatto, 2011.

VALE. Vale: nossa história. Rio de Janeiro: Verso Brasil, 2012. 420 p.

. Vale. 2016. Disponível em: < http://www.vale.com >. Acesso em: 22 Feb 2017.

WEBER, Max. Ensaios sobre a teoria das ciências sociais. São Paulo: Editora Moraes, 2003.

Recebido em: 16/01/2018

Aceito em: 31/03/2018 